\title{
STUDIES OF RIBOSE METABOLISM. VI. PATHWAYS OF RIBOSE SYNTHESIS IN MAN ${ }^{1}$
}

\author{
BY HOWARD H. HIATT \\ (From the Department of Medical Research, Beth Israel Hospital, and the Department of \\ Medicine, Harvard Medical School, Boston, Mass.)
}

(Submitted for publication May 14, 1958; accepted June 12, 1958)

Although it has been demonstrated that the pathways involved in ribose biosynthesis from hexose by a human carcinoma cell grown in tissue culture (1) and by animals in vivo (2-4) are similar, little information is available concerning in vivo mechanisms of ribose production in man. The absence of a satisfactory technique for investigating this problem led us to explore the applicability to human studies of a recently described, convenient method for "trapping" ribose in the urine of the rat (4). This procedure, which was suggested by an observation of Tabor and Hayaishi (5), involves the administration of imidazoleacetic acid (ImAA) orally or parenterally, and the subsequent isolation of imidazoleacetic acid riboside from the urine. The present report is designed to summarize ImAA toxicity studies in several animal species and to demonstrate the usefulness of the ImAA procedure for investigations of ribose synthesis in man. This technique has already been employed to demonstrate a block in the metabolism of glucuronic acid by subjects with essential pentosuria (6).

1 This investigation was aided by grants from the Jane Coffin Childs Memorial Fund for Medical Research and from the National Cancer Institute (C-3151).

\section{METHODS}

Toxicity studies. Imidazoleacetic acid dihydrochloride was dissolved in water, neutralized with $\mathrm{NaHCO}_{3}$, and administered by the routes indicated in amounts up to 3 millimoles per kilogram to mice, rats, guinea pigs and a dog. Most of the animals were watched closely for manifestations of toxicity for several hours, and then at intervals for several weeks following administration of ImAA. A guinea pig was sacrificed two weeks following injection, and specimens of several organs were excised for histologic study. ImAA was administered intravenously to a dog under light morphine anesthesia, and blood pressure, as measured with an in-lying femoral artery needle, and pulse and respiratory rates were determined for two hours thereafter.

Human studies. Three patients with short life expectancies were given ImAA and radioactive glucose or glucuronolactone. The first subject, Le, a 75 year old man with metastatic bronchogenic carcinoma, received by mouth 1,500 micromoles of ImAA dihydrochloride, an equimolar amount of sodium bicarbonate, and glucose$2-\mathrm{C}^{14}$, dissolved in $100 \mathrm{ml}$. of water, in three equal aliquots, 2 hours apart. The first dose was given 15 hours following the last ingestion of food (before breakfast), and the second and third doses, 2 and 4 hours following breakfast. Patient To, a 67 year old male with coronary artery disease, was treated in an exactly similar fashion. Patient Do, a 67 year old male with coronary artery disease, was given 2,000 micromoles each of imidazoleacetic acid and of sodium bicarbonate in a single dose by mouth,

TABLE I

Urinary ribose in human subjects given imidazoleacetic acid (ImAA)

\begin{tabular}{|c|c|c|c|c|c|c|c|c|c|}
\hline Subject & Age & Diagnosis & $\begin{array}{l}\underset{\text { admin- }}{\operatorname{ImAA}} \\
\text { istered }\end{array}$ & $\begin{array}{l}\text { Urinary } \\
\text { ribose }\end{array}$ & $\begin{array}{l}\text { Per cent } \\
\text { admin- } \\
\text { istered } \\
\operatorname{ImAA}\end{array}$ & $\begin{array}{l}\text { C14 compound } \\
\text { administered }\end{array}$ & $\begin{array}{l}\text { Molar } \\
\text { activity } \\
\text { of ribose }\end{array}$ & $\begin{array}{l}\text { Ci4 in } \\
\text { ribose }\end{array}$ & $\begin{array}{l}\text { Per cent } \\
\text { admin- } \\
\text { istered } \\
\text { C14 in }^{14} \\
\text { ribose }\end{array}$ \\
\hline Le & $\begin{array}{l}y r s . \\
75\end{array}$ & $\begin{array}{l}\text { Bronchogenic } \\
\text { carcinoma }\end{array}$ & $\begin{array}{c}\mu M \\
1,500\end{array}$ & $\begin{array}{l}\mu M \\
460\end{array}$ & 31 & $\begin{array}{l}\text { Glucose-2-C14 } \\
\left(2.86 \times 10^{7} \mathrm{cpm}\right. \\
50 \mathrm{mg} .)\end{array}$ & $\begin{array}{c}c p m / \mu M \\
32.3\end{array}$ & $1.42 \times 10^{c p m}$ & 0.050 \\
\hline To & 67 & $\begin{array}{l}\text { Coronary artery } \\
\text { disease }\end{array}$ & 1,500 & 570 & 38 & $\begin{array}{c}\text { Glucose-2-C } C^{14} \\
\left(2.86 \times 10^{7} \mathrm{cpm}\right. \\
50 \mathrm{mg} .)\end{array}$ & 26.0 & $1.48 \times 10^{4}$ & -0.052 \\
\hline Do & 67 & $\begin{array}{l}\text { Coronary artery } \\
\text { disease }\end{array}$ & 2,000 & 275 & 14 & $\begin{array}{l}\text { Glucuronolactone-U-C } \\
\left(1.57 \times 10^{7} \mathrm{cpm} ;\right. \\
67 \mathrm{mg} .)\end{array}$ & 33.0 & $9.1 \times 10^{3}$ & 0.058 \\
\hline
\end{tabular}


TABLE II

Isotope distribution in urinary ribose of subjects given imidazoleacetic acid and glucose-2- $C^{14}$

\begin{tabular}{lccccc}
\hline \multirow{2}{*}{ Subject } & \multicolumn{5}{c}{ Per cent total radioactivity in ribose carbon atoms } \\
\cline { 2 - 6 } & C-1 & C-2 & C-3 & C-4 & C-5 \\
\hline Le & 51 & 33 & 3 & 9 & 4 \\
To & 50 & 39 & 3 & 6 & 2 \\
\hline
\end{tabular}

and 15 minutes later, an intravenous injection of $5 \mathrm{ml}$. of isotonic saline containing $\mathrm{D}$-glucuronolactone-U-C ${ }^{\mathbf{1 4}}$. None of these subjects had evidence of azotemia, proteinuria or liver disease, and each had a normal fasting blood glucose.

Urine was collected in two aliquots for 24 hours following administration of the imidazoleacetic acid. All of the riboside was found in the sample collected during the first 10 hours. The procedure for isolating rat urinary ribose from the urinary imidazoleacetic acid riboside was described in detail elsewhere (4). The method used here was similar, except that instead of using the entire urine collection, one-third of the urine excreted during the first 10 hours was acidified, aerated to remove $\mathrm{CO}_{2}$, brought to $\mathrm{pH} \mathrm{8,} \mathrm{and} \mathrm{adsorbed} \mathrm{on} \mathrm{Dowex-1,} 100$ to 200 mesh, 2 per cent cross-linked, acetate form (height, 16.0 $\mathrm{cm}$.; diameter, $4.5 \mathrm{~cm}$.). The column was washed with water until the effluents were free of radioactivity, and the riboside was then eluted with $0.2 \mathrm{~N}$ acetic acid. The eluates were collected in $50 \mathrm{ml}$. fractions, and the riboside was found in fractions 5 and 6 . These were combined and treated as described previously (4). The ribose was degraded to its constituent carbon atoms by methods that have been summarized elsewhere (1). Radioactivity was measured with a "micromil" end window counter with an efficiency of 13 per cent.

Materials. Imidazoleacetic acid dihydrochloride was synthesized according to the procedure of Bauer and Tabor (7). All of the toxicity studies were carried out on the batch of ImAA subsequently used for the human studies. Uniformly $\mathrm{C}^{14}$-labeled glucuronolactone (glucuronolactone-U-C $C^{14}$, which was kindly provided by Dr. N. E. Artz of the Corn Products Refining Company, Argo, Ill., was dissolved in 0.9 per cent saline and sterilized by passage through a bacteriologic filter. This material was found to give a single radioactive spot on descending chromatography in butanol: ethanol: water $(52: 32: 16)$.

Glucose-2-C $\mathrm{C}^{14}$ was purchased from the National Bureau of Standards through the courtesy of Dr. H. S. Isbell. Degradation of the glucose to its constituent carbon

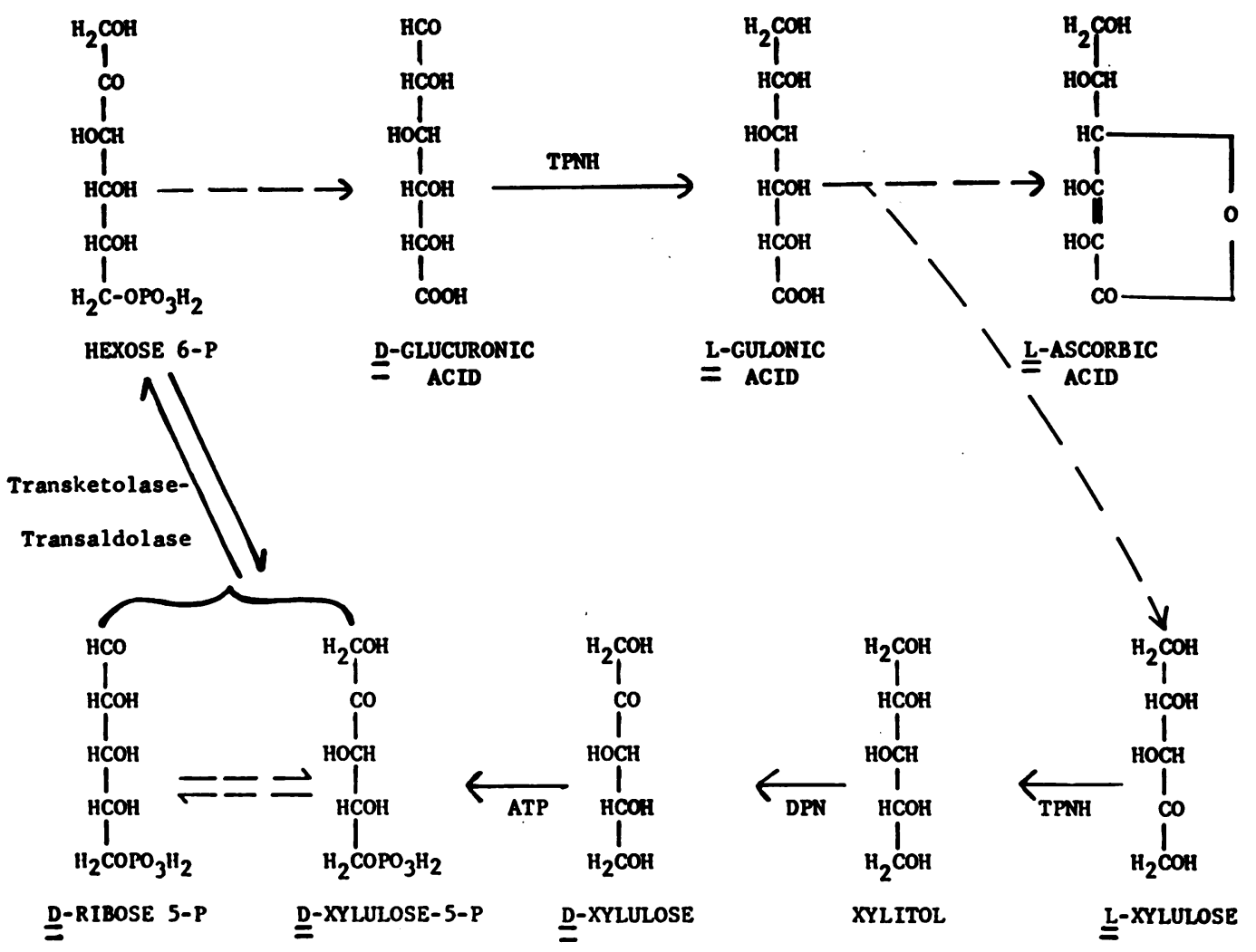

Fig. 1. Glucuronic Acid Conversion to Hexose Phosphate via the C-6 Oxidation and Pentose Phosphate Pathways 
atoms by methods previously described (8) revealed that its radioactivity was limited to carbon atom 2 .

\section{RESULTS}

\section{Toxicity studies}

The intraperitoneal administration of 2 millimoles of ImAA per $\mathrm{Kg}$. of body weight to mice and to rats had no discernible toxic effect. The administration of 3 and 4 millimoles per $\mathrm{Kg}$. to mice led to marked depression for 12 hours followed by apparently complete recovery. The intraperitoneal injection of as much as 8.5 millimoles per $\mathrm{Kg}$. to guinea pigs produced no detectable untoward effect. A guinea pig given 4 millimoles per $\mathrm{Kg}$. intraperitoneally and sacrificed two weeks later had no demonstrable abnormalities in histologic sections of lung, liver, kidney, heart and adrenal glands. The intravenous administration of 11.2 millimoles in $20 \mathrm{ml}$. of distilled water in 1 minute to a $17 \mathrm{Kg}$. dog under light morphine anesthesia led to a rise in pulse rate of 10 beats per minute, with no effect on blood pressure or respiration. The administration of an equal amount of ImAA to the same animal 30 minutes later led to no effect on any of these measurements. No immediate or delayed toxic effects were observed in the human subjects given imidazoleacetic acid.

\section{Ribose synthesis}

The human subjects excreted up to 570 micromoles of ribose as ImAA riboside (Table I). The amount of riboside excreted was greatest in Subjects To and Le, to whom the ImAA was given in divided doses over a period of several hours. In all three subjects there was appreciable $\mathrm{C}^{\mathbf{1}}$ incorporation into the urinary ribose from glucose$2-\mathrm{C}^{14}$ or glucuronolactone-C $\mathrm{C}^{14}$ (Table I).

The isotope distribution in the urinary ribose of the two subjects given glucose-2- $\mathrm{C}^{14}$ is summarized in Table II. The preponderance of radioactivity was found in carbon atoms 1 and 2, with the former more active than the latter.

\section{DISCUSSION}

These studies indicate that as much as 2 to 8.5 millimoles of imidazoleacetic acid per $\mathrm{Kg}$. of body weight can be given to some animal species without discernible toxicity. The oral administration to human subjects of less than 30 micromoles per
$\mathrm{Kg}$., on the other hand, permitted the isolation of sufficient ribose for studies of intermediary metabolism, and resulted in no untoward effects. When the ImAA was administered in divided doses over several hours, as much as 38 per cent was excreted as the riboside. However, in the patient given ImAA in a single dose only 19 per cent appeared in the urine in the glycosidic form. Tabor has previously shown that in rats given sufficiently small doses of imidazoleacetic acid as much as 80 per cent may be excreted as the riboside (9).

Isotope distribution in ribose synthesized from glucose-2-C ${ }^{14}$ is consistent with synthesis via the oxidative and nonoxidative mechanisms of the pentose phosphate pathway (10). The preponderance of isotope in carbon 1 as compared with carbon 2 is the reverse of the situation observed in a human carcinoma cell in tissue culture (1), and in normal growing rats $(3,4)$. This suggests that in our human subjects ribose production occurred predominantly by way of the C-1 oxidation pathway (the glucose 6-phosphate and 6-phosphogluconic dehydrogenase reactions). The relatively small amount of isotope randomization to carbon atoms 3,4 and 5 indicates that little dissimilation of the hexose molecule took place prior to ribose synthesis. The slight isotope excess in carbon 4 as compared with positions 3 and 5 is consistent with the aldolase cleavage of hexose- $2-\mathrm{C}^{14}$ phosphate to triose phosphates, and equilibration of the trioses, prior to triose phosphate participation in the transketolase reaction.

The implications of the study demonstrating ribose synthesis from glucuronolactone- $\mathrm{C}^{14}$ have been discussed in detail elsewhere $(6,11)$. Briefly, this experiment is considered to demonstrate the operation in man of the recently described C- 6 oxidation pathway (10) (Figure 1). This pathway is utilized by most mammalian organisms for the synthesis of ascorbic acid (12-15). Man, however, is unable to synthesize the vitamin and presumably employs this pathway only to permit the return of glucuronic acid carbon to the mainstream of carbohydrate metabolism, with the pentose, L-xylulose, as an intermediate (16). A block in this pathway has been postulated (16) to account for the urinary excretion of L-xylulose by subjects with the genetic disorder, chronic essential pentosuria (17). Strong support for this hypothesis 
was obtained in a recent study of ribose excretion by a pentosuric subject given imidazoleacetic acid and glucuronolactone-C $C^{14}(6)$. In striking contrast to Subject Do, who excreted ribose containing 0.058 per cent of the radioactive carbon present in the administered glucuronolactone, a pentosuric subject excreted ribose which was virtually free of radioactivity. The pentosuric individual, however, excreted 4,000 micromoles of L-xylulose, which contained over 4 per cent of the administered $\mathrm{C}^{14}$. The radioactivity in the L-xylulose demonstrated its origin from $\mathrm{D}$-glucuronolactone, while the absence of $\mathrm{C}^{\mathbf{1 4}}$ in the urinary ribose indicated that it was derived from sources other than the administered lactone. These data provide evidence for an impairment in the metabolism of glucuronic acid beyond the L-xylulose step in essential pentosuria.

\section{SUMMARY}

A technique is described for the study of ribose synthesis in man. This involves the oral administration of imidazoleacetic acid, which has been shown to be of exceedingly low toxicity, and the isolation of ribose from urinary imidazoleacetic acid riboside. Isotope distribution in ribose synthesized from glucose-2-C $\mathrm{C}^{14}$ by individuals with normal carbohydrate metabolism is consonant with ribose biosynthesis from hexose via the oxidative and the nonoxidative reactions of the pentose phosphate pathway. An additional mechanism of ribose biosynthesis, from glucuronic acid, is indicated by the excretion of ribose- $\mathrm{C}^{\mathbf{1 4}}$ by a human subject given imidazoleacetic acid and D-glucuronolactone. A block in this pathway has previously been shown to be responsible for the excretion of L-xylulose by individuals with chronic essential pentosuria.

\section{ACKNOWLEDGMENTS}

These studies were greatly facilitated by many invaluable suggestions by $\mathrm{Dr}$. Herbert Tabor. The expert technical assistance of Misses Jacqueline Lareau and Madeline Goldstein is gratefully acknowledged. Dr. David Freiman kindly prepared and reviewed the histologic sections.

\section{REFERENCES}

1. Hiatt, H. H. Studies of ribose metabolism. I. The pathway of nucleic acid ribose synthesis in a human carcinoma cell in tissue culture. J. clin. Invest. 1957, 36, 1408.

2. Bernstein, I. A. Synthesis of ribose by the rat. Biochim. biophys. Acta 1956, 19, 179.

3. Marks, P. A., and Feigelson, P. The biosynthesis of nucleic acid ribose and of glycogen glucose in the rat. J. biol. Chem. 1957, 226, 1001.

4. Hiatt, H. H. Studies of ribose metabolism. II. A method for the study of ribose synthesis in vivo. J. biol. Chem. 1957, 229, 725.

5. Tabor, H., and Hayaishi, O. The excretion of imidazoleacetic acid riboside following the administration of imidazoleacetic acid or histamine to rats. J. Amer. chem. Soc. 1955, 77, 505.

6. Hiatt, H. H. Studies of ribose metabolism. IV. The metabolism of ${ }^{-D}$-glucuronolactone in normal and pentosuric human subjects. Biochim. biophys. Acta 1958, 28, 645.

7. Bauer, $H$., and Tabor, $H$. The synthesis of imidazoleacetic acid. Biochem. Prep. 1957, 5, 97.

8. Hiatt, H. H., Goldstein, M., Lareau, J., and Horecker, B. L. The pathway of hexose synthesis from pyruvate in muscle. J. biol. Chem. 1958, 231, 303.

9. Tabor, $\mathrm{H}$. The fate of histamine in the body in Ciba Foundation Symposium on Histamine. Boston, Little, Brown \& Co., 1956, p. 318.

10. Horecker, B. L., and Hiatt, H. H. Pathways of carbohydrate metabolism in normal and neoplastic cells. New Engl. J. Med. 1958, 258, 177 and 225.

11. Hiatt, H. H., and Lareau, J. Studies of ribose metabolism. VII. An assessment of ribose biosynthesis from hexose via the C-6 oxidation pathway. J. biol. Chem. Oct., 1958.

12. Horowitz, H. H., and King, C. G. Glucuronic acid as a precursor of ascorbic acid in the albino rat. J. biol. Chem. 1953, 205, 815.

13. Ashwell, G. Enzymatic degradation of D-galacturonic and D-glucuronic acid. Fed. Proc. 1957, 16, 146.

14. Bublitz, C., Grollman, A. P., and Lehninger, A. L. Enzymatic conversion of D-glucuronate to L-ascorbate in animal tissues. Fed. Proc. 1957, 16, 382.

15. Burns, J. J., and Evans, C. The synthesis of L-ascorbic acid in the rat from $\mathrm{D}$-glucuronolactone and L-gulonolactone. J. biol. Chem. 1956, 223, 897.

16. Touster, O., Hutcheson, R. M., and Rice, L. The influence of $\mathrm{D}$-glucuronolactone on the excretion of L-xylulose by humans and guinea pigs. J. biol. Chem. 1955, 215, 677.

17. Enklewitz, M., and Lasker, M. The origin of L-xyloketose (urine pentose). J. biol. Chem. 1935, 110, 443. 